\title{
Esophageal Calcification After Corrosive Injury
}

\author{
H. Jaeger, K. Mathias \\ Department of Diagnostic Radiology, Teaching Hospital Dortmund, Beurhausstrasse 40, D-44137 Dortmund, Germany
}

Received: 19 May 1993/Accepted: 23 June 1993

\begin{abstract}
A clinically silent case of intramural esophageal calcification secondary to corrosive injury is presented. Computed tomography (CT) demonstrated a circular calcified esophageal wall over a distance of $5 \mathrm{~cm}$ leaving a residual esophageal lumen of $5 \mathrm{~mm}$.
\end{abstract}

Key words: Esophagus, calcification-Esophagus, corrosive injury - Chest radiograph-Barium swallow CT.

Multiple reports describe the sequelae of corrosive injury to the esophagus and the radiological features including stricture formation and development of esophageal carcinoma [1-7].

We present a patient with circular calcification of the esophageal wall following corrosive injury 45 years ago.

\section{Case Report}

A 52-year-old woman was admitted with the sonographic diagnosis of liver cysts that were diagnosed by her physician incidentally during routine check-up for mental problems. Her medical history included a Billroth II gastric resection for recurrent gastric ulcers 21 years ago, treatment for alcohol abuse 2 years ago, and glaucoma. As a child, at the age of 7 , she had swallowed incidentally a corrosive liquid and was treated conservatively at that time. She did not complain of dysphagia and had never sought medical attention for that problem. She could swallow any liquid and solid food, but admitted that she always chewed very thoroughly her food before swallowing. Except for eye drops for glaucoma she was on no medications, she denied any alcohol intake for the last 2 years, and smoked one pack of cigarettes per day.

Routine chest radiographs in the lateral view revealed a streaky calcification in the retrocardial space (Fig. 1A). Fluoroscopic examination confirmed the presence of the calcification. Barium swallow showed the barium column in the sagittal and lateral view within the calcification (Fig. 1B). There was some narrowing of the esophageal

Correspondence to: $\mathrm{H}$. Jaeger lumen at the calcification, but without esophageal dilatation proximally to it. The act of swallowing was normal. Further assessment with a CT scan demonstrated a circular calcified esophageal wall of $5 \mathrm{~mm}$ thickness over a distance of $5 \mathrm{~cm}$ leaving a residual esophageal lumen of $5 \mathrm{~mm}$ (Fig. 2).

The liver cysts were punctured several times under sonographic control and injected with sclerosing agents. Because she had no dysphagia, she was not treated for esophageal changes.

\section{Discussion}

The course of corrosive damage to the intestinal tract is divided into three phases [2]. In the first phase, 1 to 4 days after ingestion, acute necrosis with intensive inflammatory reaction in surrounding tissue occurs, followed by the second phase, 3 to 5 days after ingestion, in which sloughing of necrotic tissue occurs and repair begins with fibroblastic activity. The third phase starts 3 to 4 weeks after ingestion, when the fibrous tissue begins to contract and the inflammatory reaction subsides. Contraction of the fibrous tissue and adhesions between granulating areas in the lumen lead to stricture formation. Depending on the severity of the injury the mucosa and submucosa may regenerate.

Stricture formation is the leading radiological feature of the chronic phase of corrosive esophageal injury with prestenotic dilation of the esophagus in severe stenosis $[2,3,5]$. It occurs in up to $30 \%$ of all patients. Characteristically, it shows no mucosal folds in the region of the stricture with smooth, concentric tapering of the esophageal wall at the margins, but overhanging margins and an irregular lumen with ulceration are also possible [2-5]. A further radiological sign seen on chest radiographs is an abnormal pleural reflection due to widening of periesophageal tissue, caused by fibrosis in this area $[1,2]$.

We add another radiological sign to the chronic phase of corrosive esophageal injury, to our knowledge not yet reported, calcification of the esophageal wall. 

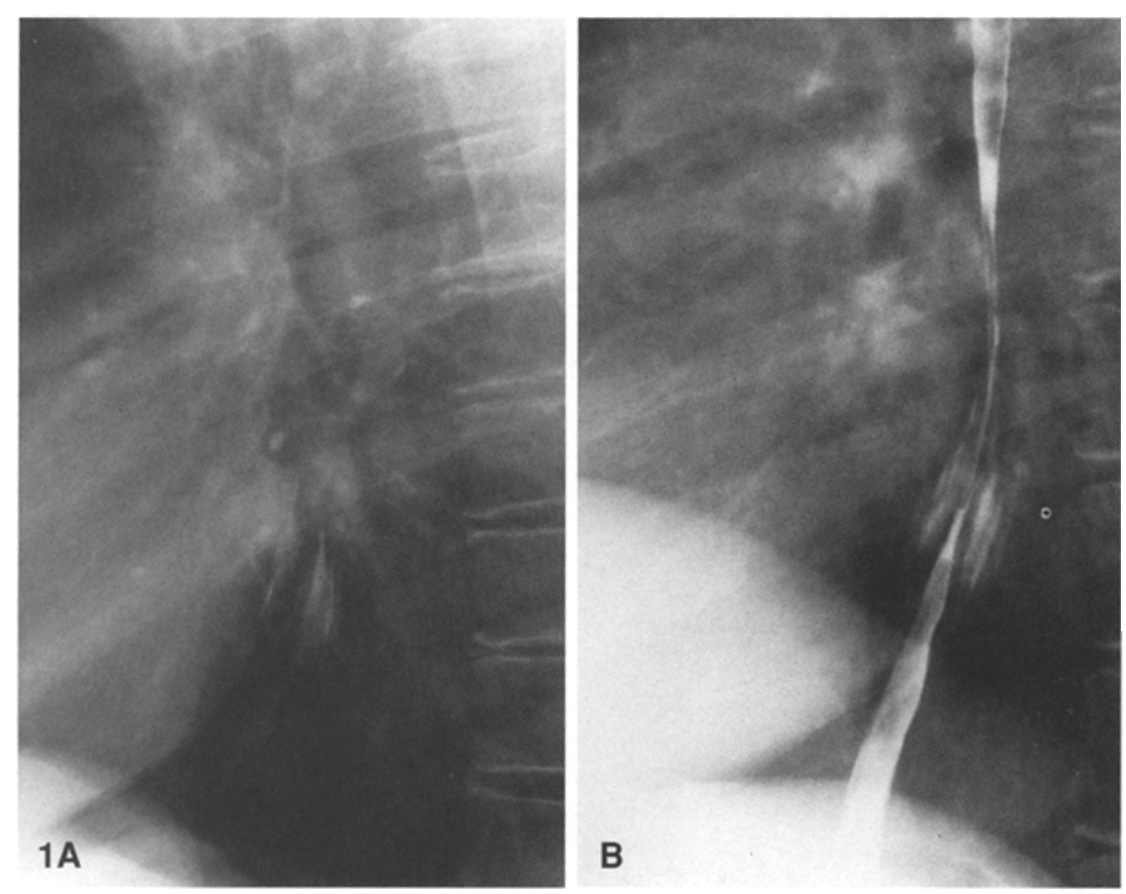

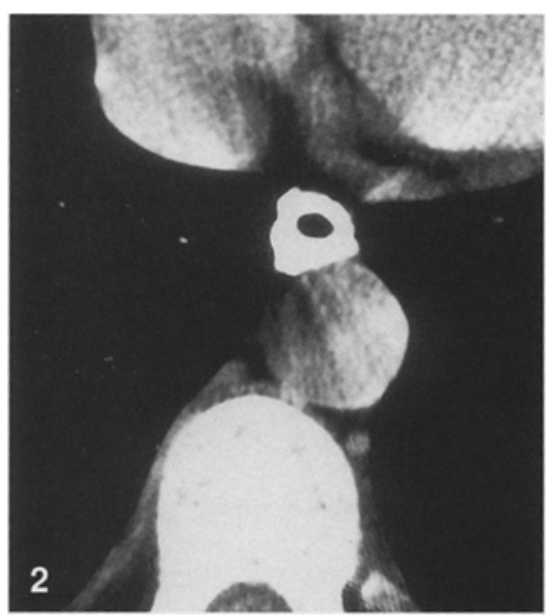

Fig. 1. A Lateral chest radiograph reveals streaky calcifications in the retrocardial space. B Barium swallow shows the barium column in the lateral view within the streaky calcifications.

Fig. 2. CT scan demonstrates a circular calcified esophageal wall of $5 \mathrm{~mm}$ thickness. The esophagus has a residual lumen of $5 \mathrm{~mm}$.
Pathologically, this can be explained by dystrophic calcification of chronic inflammatory granulation tissue that forms as a reaction to the injury of the esophageal wall. If the calcification is extensive enough, it can already be seen on the chest radiographs and can be confirmed by barium swallow and CT scan, which will demonstrate the whole extent and thickness of the calcification.

It is interesting that our patient was almost asymptomatic, although she had a residual esophageal lumen of only $5 \mathrm{~mm}$ over a distance of $5 \mathrm{~cm}$, completely rigid and without peristalsis due to the almost complete circular calcification of the esophageal wall. It has been reported that an esophageal lumen less than $12 \mathrm{~mm}$ in diameter virtually assures dysphagia and that an esophageal diameter of $20 \mathrm{~mm}$ allows the asymptomatic intake of a diet [8]. The diameter of the esophageal lumen is only one factor that influences the occurrence of dysphagia. The others are the length and the degree of elasticity of the stricture, although the chewing habits of the patient may be even more important [9]. It seems that even with a very narrow, long, and rigid stricture, a patient that has completely adapted and always chews their food, thoroughly and carefully, may be asymptomatic.

Nevertheless, patients with a history of caustic injury to the esophagus should be regularly followed for detection of symptoms and development of carcinoma, which has been reported to occur 22 times more often in patients with caustic injury than in the normal population [7].

\section{References}

1. Martel W. Radiologic features of esophagogastritis secondary to extremely caustic agents. Radiology 1972;103:31-36

2. Franken EA. Caustic damage of the gastrointestinal tract: roentgen features. A.IR 1973;118:77-85

3. Bruna J, Janecka V, Skatula L. Das Röntgenbild der Verätzung von Speiseröhre und Magen durch Säuren und Laugen. Fortschr Röntgenstr 1972;117:557-562

4. Koischwitz D, Sobbe A, Miederer SE, Stadelmann O. Die benigne intraluminale Ösophagusstenose. Fortschr Röntgenstr 1974;121:161-175

5. Frommhold H, Rohner HG, Koischwitz D, Kühr J. Das Röntgenbild kaustischer Veränderungen des oberem Intestinaltraktes. Fortschr Röntgenstr 1976;125:514-520

6. Rohner HG, Lelbach WK, Müller RP, Kühr J. Das endoskopische Bild der fruihen Spätphase nach Säureverätzung des Magens. Leber Magen Darm 1974;4:153-157

7. Joske RA, Benedikt EB. The role of benign esophageal obstruction in the development of carcinoma of the esophagus. Gastroenterology 1959;36:749-755

8. McLean GK, Cooper GS, Hartz WH, Burke DR, Meranze SG. Radiologically guided balloon dilation of gastrointestinal strictures. Part I. Techniques and factors influencing procedural success. Radiology 1987; 165:35-40

9. Song H, Han Y, Kim H, Kim C, Choi K. Corrosive esophageal stricture: safety and effectiveness of balloon dilation. Radiology $1992 ; 184: 373-378$ 